\section{Calculating greenhouse budgets}

SIR-The global warming potentials (GWPs) proposed by Lashof and Ahuja ${ }^{1}$ provide a useful step towards a system for converting sources (and sinks) of various greenhouse gases into common greenhouse units. Others ${ }^{2}$ have also derived GWPs, and the Intergovernmental Panel on Climate Change (IPCC) is soon to report on various related issues. But I would like to caution against premature reliance on a GWP scale as a central component of a greenhouse treaty.

Assessing GWPs requires an accurate numerical accounting of three factors for each gas: (1) direct (instantaneous) greenhouse forcing; (2) indirect effects; and (3) atmospheric residence time. The first factor is relatively undisputed, but the other two are not. Regarding indirect effects, the GWPs for chemically active gases - $\mathrm{CO}$, tropospheric $\mathrm{O}_{3}$ precursors and $\mathrm{CH}_{4}-$ depend on a complex mix of those gases, $\mathrm{NO}_{r}$ and other factors related to the chemical environment into which they are released. The magnitude of indirect effects varies spatially and temporally ${ }^{3}$, suggesting the need for GWPs based at least on several chemically coherent regions (such as urban midlatitude, clean midlatitude, tropical) rather than a single, global GWP.

Accounting for residence times is even more complex as behaviour of atmospheric $\mathrm{CO}_{2}$ differs fundamentally from the other greenhouse gases. Lashof and Ahuja have approached this using MaierReimer and Hasselmann's ocean model ${ }^{+}$, from which they calculate an "effective residence time" of 230 years. However, the response to $\mathrm{CO}_{2}$ input is sensitive to the temporal pattern of emissions (see Table 2 of ref. 4). Under conditions of continuous and exponential growth, long-term response plays little part in determining oceanic uptake. This has been the case for the past few decades, during which roughly half of the $\mathrm{CO}_{2}$ emitted into the atmosphere has been absorbed - a situation not adequately described using long residence times as uptake is dominated by short-term processes. Conversely, under conditions of declining emissions there is tighter coupling of emissions to longer-term oceanic processes (mixing below the thermocline). Harvey has argued that the fraction of $\mathrm{CO}_{2}$ can even be managed at zero (no net increase in greenhouse forcing from $\mathrm{CO}_{2}$ ) if emissions are initially reduced by about half. Although the fully integrated "effective residence time" may remain roughly the same under these different conditions, the response functions are clearly different. Thus, the pattern of emissions also affects the sensitivity of a $\mathrm{CO}_{2}$-based GWP to the relative importance of short and long-term contributors to global warming (as reflected in the discount rate and the time interval of integration). Perhaps different scales of GWPs should be established for countries with different emission patterns.

Finally, how can GWPs be applied to the political process? GWPs are at present based on somewhat arbitrary assumptions and are fraught with uncertainty and complexity. Results from models of oceanic uptake of $\mathrm{CO}_{2}$ vary considerably, and Tans et al. ${ }^{6}$ suggest an important (but controversial) role for the terrestrial biota in net $\mathrm{CO}_{2}$ consumption. These carbon cycle factors significantly affect the assumed "effective residence time" for $\mathrm{CO}_{2}$ and, therefore, the GWP scale, as the non- $\mathrm{CO}_{2}$ components of the latter are inversely proportional to the former. For example, using the plausible 120-year residence time adopted by Rodhe ${ }^{2}$ instead of 230 years roughly doubles the GWP of $\mathrm{N}_{2} \mathrm{O}$.

Several nations that have acknowledged the utility of GWPs would also like to sign a greenhouse treaty at the 1992 UN Conference on Environment and Development. Given that political schedule and the uncertainty of the scientific basis of GWPs, insistence on use of this parameter will delay and may misdirect a legal regime to control global warming, especially if that regime is highly quantified. Even small shifts in GWPs will have high financial and political consequences. So if they are used, it must be clear well in advance what rules apply to the process of changing the GWP scale.

Despite the theoretical appeal of GWPs, it is important for a greenhouse regime to be relatively insensitive to inevitable fluctuations in them. This probably means that there will have to be independent control plans for $\mathrm{CO}_{2}$ and for non- $\mathrm{CO}_{2}$ gases. Moreover, as widely noted $^{1,7-9}$ the absence of reliable, costeffective measures to monitor emissions of non- $\mathrm{CO}_{2}$ greenhouse gases (except chlorofluorocarbons) suggests there may be little gained for the goal of a verifiable multi-gas greenhouse regime, even if there is some political agreement on appropriate GWP values.

\section{Department of Political Science,}

Massachusetts Institute of Technology,

Cambridge, Massachusetts 02139, USA

1. Lashof, D.A. \& Ahuja, D.R. Nature 344, 529-531 (1990).

2. Rodhe, H. Science 248, 1217-1219 (1990)

3. Thompson, A.M., Huntley, M.A. \& Stewart, R.W. J. geo phys. Res. 90, 9829-9844 (1990) (1987)

5. Harvey, L.D.D. Clim. Change 15, 343-381 (1989)

6. Tans, P.P., Fung, I.Y. \& Takahashi, T. Science 247 1431-1438 (1990).

Trubb, M. The Greenhouse Effect: Negotiating Targets (Royal Institute of International Affairs, London, 1989).

8. Victor, D.G. Discussion Paper G-90-06 (Energy and Environmental Policy Center, John F. Kennedy School of Government, Harvard University, Cambridge, 1990)

9. Victor, D.G. Policy Sciences (in the press).
4. Maier-Reimer, E. \& Hasselmann, K. Clim. Dyn. 2, 63-90

\section{Origins of fetal handedness}

SIR - The origins of behavioural asymmetries - in particular handedness - are a topic of continued interest. We have now found evidence of a behavioural asymmetry in the fetus - a preference for sucking the thumb of the right hand.

In the human population as a whole some 90 per cent exhibit a bias for the right hand $^{1}$. In our study we used real-time ultrasound to observe thumb-sucking by the fetus in 224 women who had normal, singleton, uncomplicated pregnancies. Our results, presented in the table, reveal a clear bias for sucking the thumb of the right hand, only 12 of 224 (5.4 per cent) fetuses favouring the left. The

FETAL THUMB PREFERENCE

Gestational age (weeks)

15-21 28-34 36-term Total

$\begin{array}{lllll}\text { Right thumb } & 52 & 76 & 84 & 212\end{array}$

$\begin{array}{lllll}\text { Left thumb } & 4 & 3 & 5 & 12\end{array}$

$\begin{array}{lllll}z & 6.28 & 8.11 & 8.27 & 13.302\end{array}$

$P<$

$\begin{array}{llll}0.0001 & 0.0001 & 0.0001 & 0.0001\end{array}$

The number of individuals observed sucking either their left or right thumb at different gestational ages ( $n=224)$. $z$, Right thumb bias.

intrauterine position of the fetus had no effect on thumb preference. Repeated observations of 17 fetuses indicated that preference for a particular thumb is maintained during pregnancy. Furthermore, fetal thumb preference correlates highly with neonatal head-position preference $(P=0.002)$.

Our study demonstrates for the first time the existence of behavioural asymmetries before birth. Evidence of handedness in fetuses of normal uncomplicated pregnancies raises questions for theories proposing that laterality results from prenatal or birth injury ${ }^{2}$ but supports genetic explanations of handedness ${ }^{3}$. One could speculate that although the initial bias is a result of advanced right-sided neuromuscular development, its maintenance results from reinforcing aspects of thumb-sucking. Indeed it may be that sucking a particular thumb differentially stimulates the left and right brain and thus commences the development of brain lateralization prenatally.

Peter G. HePper SARA SHAHIDULLAH RAYMOND WHITE

Fetal Behaviour Investigations,

School of Psychology,

Queen's University of Belfast,

Belfast BT7 1NN, UK

1. Porac, C. \& Coren, S. Lateral Preferences and Human Behavior (Springer, New York, 1981)

. Satz, P. Neuropsychologia 11, 115-117 (1973)

3. Annett, M. Left, Right, Hand and Brain: The Right Shift Theory (LEA, Hillsdale, New Jersey, 1985) 